\title{
Rheological, mechanical and morphological properties of poly(methyl methacrylate)/poly(ethylene terephthalate) blend with dual reactive interfacial compatibilization
}

\author{
Juciklécia da Silva Reinaldo ${ }^{1}$, Maria Carolina Burgos Costa do Nascimento ${ }^{1}$, Edson Noriyuki Ito ${ }^{1 *}$ \\ and Elias Hage Junior ${ }^{2}$ \\ 'Departamento de Engenharia de Materiais, Universidade Federal do Rio Grande do Norte - UFRN, \\ Natal, RN, Brazil \\ ${ }^{2}$ Departamento de Engenharia de Materiais, Universidade Federal de São Carlos - UFSCar, \\ São Carlos, SP, Brazil \\ *ito@ufrnet.br
}

\begin{abstract}
In this work, the rheological, mechanical and morphological behavior of immiscible blend poly (methyl methacrylate)

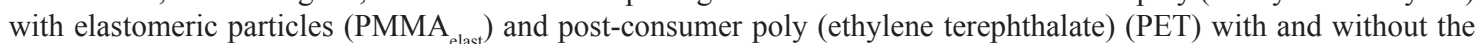
use of the interfacial compatibilizer poly (methyl methacrylate-co-glycidyl methacrylate-co-ethyl acrylate) (MGE) was studied. The significant increase in torque presented in rheological analyses has shown a indication of chemical reactions between the epoxy group of MGE with end groups of PET chains and also with the elastomeric phase of PMMA elast The increased concentration of PET yielded an increase in maximum strength and elasticity modulus and a decrease in elongation at break. The PMMA ${ }_{\text {elast }} /$ PET binary blend $(50 / 50 \mathrm{wt} \%)$ and $\mathrm{PMMA}_{\text {elast }} / \mathrm{PET} / \mathrm{MGE}$ compatibilized blend $(65 / 30 / 5 \mathrm{wt} \%)$ showed pronounced results in elongation at break compared to PMMA $\mathrm{A}_{\text {elast}}$, whereas, in the first results were due to the evidence of a co-continuous morphological structure and in the second, due to the efficiency of the dual reactive interfacial compatibilization of $\mathrm{PMMA}_{\text {elast }} / \mathrm{PET}$ blends. Scanning electron microscopy (SEM) and transmission electron microscopy (TEM) analyses showed that PMMA ${ }_{\text {elast }} / \mathrm{PET} / \mathrm{MGE}$ blends exhibit complex phase morphology due to the presence of elastomeric particles in the PMMA ${ }_{\text {elast }}$ copolymer and in the use of MGE terpolymer.
\end{abstract}

Keywords: PMMA copolymer, post-consumer PET, morphology, reactive extrusion.

\section{Introduction}

Polymer blends seem to be a viable alternative to obtain new polymeric materials with properties usually not found in a single polymer. The interest both academic and industrial to produce and refine new materials through the mechanical mixing of commercially available polymers has grown significantly each day. This approach is relatively simple and commercially attractive compared to the synthesis of new polymers ${ }^{[1-3]}$.

Poly (methyl methacrylate) (PMMA) is a polymer belonging to the class of methacrylates and shows many possibilities for technological applications. Due to its amorphous structure, PMMA is a transparent material that exhibits good optical properties ${ }^{[4-6]}$. It is widely used in applications replacing glass, which require transparency and good resistance. However, PMMA is brittle at room temperature with low elongation at break and low impact strength. A very common method to promote improvements in the mechanical properties of PMMA is its toughening with elastomers $^{[7-12]}$.

The addition of elastomers in PMMA become the polymer opaque and lose transparency, one of its most important characteristics of this material. A solution to this problem is the addition of MBS copolymers (methyl methacrylatebutadiene-styrene) or MABS (methyl methacrylateacrylonitrile-butadiene-styrene), which do ot change the
PMMA transparency because the refraction index of these elastomers is close to the PMMA. Studies in literature show that the addition of MBS to PMMA does not change its transparency and improves its mechanical properties, especially elongation at break and impact strength ${ }^{[7,13-17]}$.

PET is a polymer belonging to the group of polyesters, produced by the condensation reaction between terephthalic acid and ethylene glycol. This polymer can be found in different percentage of crystallinity: in the amorphous form (transparent), partially crystalline and oriented (translucent) or with a high degree of crystallinity (opaque). Due to its good mechanical performance, chemical resistance, transparency, processability and reasonable thermal stability, PET has ideal characteristics for the manufacture of a wide variety of products in the packaging sector such as soft drinks, water, juices, edible oils, etc., in addition to durable items used in electronics and automobiles ${ }^{[6,18-21]}$.

Bottle grade PET (PETG) has $2 \%$ by weight of terephthalic acid replaced by isophthalic acid, and this structural change hinders crystallization, retarding it sufficiently so that the maximum degree of crystallinity during stretching in the blow molding process does not exceed $35 \%$, providing a semi-crystalline, transparent and resistant product. The PETG was developed to replace glass ${ }^{[22]}$. 
One of the major problems of society is the post-consumer waste. PET is a plastic material widely found in garbage, which takes over 100 years to degrade in the environment ${ }^{[23-26]}$. A viable alternative for the recycling of plastic materials with higher added value, such as PET used as soft drink bottles is the development of polymer blends. PMMA/PET blend can be a form of conscious reuse of post-consumer PET, decreasing the accumulation of this material in landfills and helping the environment ${ }^{[27]}$.

PMMA/PET blends are mainly use in electrical and automotive applications, which require materials with good dimensional stability especially for electronic circuit equipment. PET is a material with good dimensional stability in the temperature range from 0 to $100{ }^{\circ} \mathrm{C}^{[6]}$, its use in mixtures promotes improvements in the PMMA properties, which is an amorphous polymer that may exhibit variations in its dimensional stability. Furthermore, it can also reduce production costs by replacing part of virgin PMMA resin by post-consumer PET ${ }^{[27,28]}$.

Most immiscible blends have unstable phase morphology and often lower properties compared to pure polymers, requiring the addition of an interfacial compatibilizer. The use of compatibilizers in these immiscible systems must accomplish: (i) optimization of the interfacial tension, i.e., the degree of dispersion; ii) stabilize the morphology against high stresses during forming, and (iii) enhance adhesion between the phases in the solid state ${ }^{[29-31]}$.

Studies in literature with poly (butylene terephthalate) (PBT) and poly (styrene-co-acrylonitrile) (SAN) blends ${ }^{[32,33]}$ have shown that poly (methyl methacrylate-co-glycidyl methacrylate-co -ethyl acrylate) (MGE) is an efficient compatibilizer for the PBT/SAN system. These studies showed that MGE has miscibility with SAN copolymer according to the acrylonitrile concentration in the SAN, and also there is a chemical reaction of end groups of the carboxylic and hydroxyl chains of PBT.

Torque rheometry provides, by monitoring torque as a function of time, evidence of the occurrence of chemical reactions between components of the polymer blend. And also interfacial compatibilizer, which increase the torque, promote a chemical reactions with in situ formation of a copolymer (reactive extrusion) during processing of the polymer blend ${ }^{[34-36]}$.

In the work developed by Ito et al. ${ }^{[37]}$, the torque rheometry results showed no increase in torque with the addition of compatibilizer MGE to the $\mathrm{PMMA}_{\text {homo }} /$ silica/MGE composition (96/2/2 wt \%) when compared with the torque value of pure $\mathrm{PMMA}_{\text {homo }}$. On the other hand, the PMMA elast $_{\text {silica/MGE }}$ composition (96/2/2 wt \%) showed a significant increase in torque compared to pure PMMA elast, $_{\text {indicating that there was }}$ no reaction between MGE and silica. Thus, the occurrence of reactions between PMMA elast $_{\text {and }}$ MGE was verified.

Studies conducted by Dewangan and Jagtap ${ }^{[38]}$ showed that the addition of PtBA- $b$-PMMA compatibilizer, which has acidic functional groups that react with end groups of hydroxyl chains present in PET, synergistically affects the mechanical properties of the PMMA/PET binary blend.

Dantas $^{[39]}$ showed that the increase of PET percentage as dispersed phase in the PMMA homo $_{\text {PET binary blend }}$ caused a significant increase in the average diameter of the dispersed phase. In relation to the use of MGE compatibilizer, it was observed that there was a reduction in the average diameters of the dispersed phase for compositions with the same percentage of PET.

Due to the incompatibility and immiscibility of the PMMA/PET binary blend, it is necessary to use a compatibilizer to improve the properties of this blend. Therefore, the aim of this study was to correlate the rheological, mechanical and morphological properties of poly (methyl methacrylate) copolymerized with elastomer and post-consumer poly (ethylene terephthalate) binary blend with and without the use of compatibilizer MGE until to phase inversion.

\section{Experimental}

\subsection{Materials}

This study used two types of poly (methyl methacrylate) (PMMA): poly (methyl methacrylate) homopolymer $\left(\mathrm{PMMA}_{\text {homo }}\right)$ (ECL-DH); poly (methyl methacrylate) copolymerized with elastomeric particles $\left(\right.$ PMMA $\left._{\text {elast }}\right)($ ECP800); both acquired from Unigel SA with melt flow indexes of 1.2 and $3.8 \mathrm{~g} / 10 \mathrm{~min}$ (standard ASTM D1238, $230{ }^{\circ} \mathrm{C} / 3.8 \mathrm{~kg}$, obtained from the supplier), respectively. Poly (ethylene terephthalate) (PET) was obtained from soft drink bottles with melt flow index of $15 \mathrm{~g} / 10 \mathrm{~min}$ (standard ASTM D1238, $250^{\circ} \mathrm{C} / 2.16 \mathrm{~kg}$, measured by the authors). Poly (methyl methacrylate-coglycidyl methacrylate-co-ethyl acrylate) (MGE), used as compatibilizer, was synthesized in laboratory according to methodology described in literature ${ }^{[32,33]}$.

The formulations of polymer blends used for rheological, mechanical and morphological characterization, and solvents used for the extraction of phase in the morphology of the $\mathrm{PMMA}_{\text {elast }} / \mathrm{PET}$ binary blends and PMMA ${ }_{\text {elast }} / \mathrm{PET} / \mathrm{MGE}$ compatibilized blends are showed in Table 1.

\subsection{Rheological characterization}

Table 1 shows the polymer blends used in the characterization of the rheological behavior of mixtures that were performed using a PolyLab Haake torque rheometer model Reomix 600, rotation speed of $100 \mathrm{rpm}$, temperature of $240{ }^{\circ} \mathrm{C}$, mixing chamber of $69 \mathrm{~cm}^{3}$ with $70 \%$ of filled volume, and processing time of 15 minutes.

\subsection{Extrusion and injection molding processing}

The compositions of polymer blends used in the characterization of the mechanical and morphological behaviors are shown in Table 1. The mixtures were prepared in a co-rotating twin screw extruder from company AX Plásticos Máquinas Técnicas LTDA, $\mathrm{D}=16 \mathrm{~mm}$ and $\mathrm{L} / \mathrm{D}=40$, using a temperature profile of $102 / 160 / 190 / 210 / 220 / 230 / 220 / 210^{\circ} \mathrm{C}$ from the feeding zone to the matrix. The materials were added into the feed hopper at $80 \mathrm{rpm}$ and screw rotation speed of $220 \mathrm{rpm}$. After extrusion, the formulations of polymer blends were granulated and dried in a circulating air oven $\left(\right.$ at $60^{\circ} \mathrm{C}$ for 12 hours) and then in vacuum (at $60^{\circ} \mathrm{C}$ for 12 hours). The molding of test specimens for tensile strength analysis (ASTM D638-01) was performed in an Arburg injection molding machine, model $270 \mathrm{~V}$, with temperature profile 
of $230 / 240 / 240 / 250 / 250^{\circ} \mathrm{C}$, molding temperature of $50{ }^{\circ} \mathrm{C}$ and cooling time equal to $50 \mathrm{~s}$.

\subsection{Mechanical characterization}

Uniaxial tensile tests were performed in a Shimadzu universal testing machine model AG - $300 \mathrm{kN}$, speed of $1 \mathrm{~mm} \cdot \mathrm{min}^{-1}$ up to $0.5 \%$ and strain of $5 \mathrm{mim} \cdot \mathrm{min}^{-1}$ until failure. For calculation of the elasticity modulus, speed of $1 \mathrm{~mm} \cdot \mathrm{min}^{-1}$ was used, using segment mode between 0.05 and $0.25 \%$ of strain.

\subsection{Morphological characterization}

\subsubsection{Scanning electron microscopy}

Samples were cryo-fractured in liquid nitrogen and then phase extraction was performed with chloroform and a phenol/1,1,2,2-tetrachloroethane solution (60/40 wt\%) (Table 1) under mechanical stirring in ultrasound for 5 and 15 minutes. Samples were placed on SEM specific support and metallized with a thin gold layer. Morphological analyses were performed using a Philips scanning electron microscope model XL-30 FEG.

\subsubsection{Transmission electron microscopy}

Samples collected from the center of the tensile specimen were cataloged and prepared by reducing the sample cross-sectional area (trimming) and sizing the sample tip to be cryo-ultramicrotomized in the trapezoidal form, which provides better stress distribution in the cutting of films, with surface area of approximately $0.5 \mathrm{~mm}^{2}$.

Then, samples were sectioned on a Leica ultramicrotome model Reichert Ultracut S using a diamond knife (Diatome CryoHisto $45^{\circ}$ ), temperature of $-60^{\circ} \mathrm{C}$ cooled with liquid

Table 1. Formulations of polymer blends used for rheological, mechanical and morphological characterization, and solvents used in function of the morphologies.

\begin{tabular}{cccc}
\hline Materials & $\begin{array}{c}\text { Rheological } \\
\text { Studies } \\
\text { (wt\%) }\end{array}$ & $\begin{array}{c}\text { Mechanical } \\
\text { and } \\
\text { Morphological } \\
\text { (wt\%) }\end{array}$ & Solvents \\
\hline PMMA $_{\text {elast }}$ & 100 & 100 & $* 1$ and *2 \\
PMMA homo $_{\text {PET }}$ & 100 & - & - \\
MGE & 100 & 100 & - \\
PMMA $_{\text {elast }} /$ MGE & 100 & - & - \\
PMMA $_{\text {homo }} /$ MGE & $95 / 5$ & - & - \\
PMMA $_{\text {elast }} /$ PET & $95 / 5$ & - & - \\
PMMA $_{\text {elast }} /$ PET & $85 / 15$ & $85 / 15$ & $* 2$ \\
PMMA $_{\text {elast }} /$ PET & $70 / 30$ & $70 / 30$ & $* 1$ \\
PMMA $_{\text {elass }} /$ PET & $50 / 50$ & $50 / 50$ & $* 1$ \\
PMMA $_{\text {elast }} /$ PET & $30 / 70$ & $30 / 70$ & $* 1$ \\
PMMA $_{\text {elast }} / \mathrm{PET} / \mathrm{MGE}$ & $80 / 15 / 5$ & $80 / 15 / 5$ & $* 2$ \\
PMMA $_{\text {elast }} / \mathrm{PET} / \mathrm{MGE}$ & $65 / 30 / 5$ & $65 / 30 / 5$ & $* 1$ and $* 2$ \\
\hline
\end{tabular}

*1 - Chloroform (solvent to PMMA $\mathrm{A}_{\text {am }}$ and elastomeric particles). *2 - Phenol / 1,1,2,2-tetrachloroethane (60/40 wt\%) (solvent to PET and elastomeric particles). nitrogen to avoid deformation of the original microstructure, cutting rate of $0.2 \mathrm{~mm} \cdot \mathrm{s}^{-1}$ and sample thickness of $25 \mathrm{~nm}$.

The sliced samples were exposed to ruthenium tetroxide vapor $\left(\mathrm{RuO}_{4}\right)$ for 4 hours for the incorporation of atoms of high atomic number into the PET phase and to generate a contrast between domains of the dispersed phase in relation to the continuous phase. Morphological analyses, obtained by TEM, were carried out with a Philips model CM120, using voltage of $120 \mathrm{kV}$. Subsequently, Image Pro Plus software version 4.5 (Media Cybernetics) was used to determine the average diameter of particles based on photomicrographs obtained.

\section{Results and Discussion}

\subsection{Rheological characterization}

The analysis of the reactivity of pure polymers ( PMMA $_{\text {homo }}$, $\mathrm{PMMA}_{\text {elast }}$ and PET) with the interfacial compatibilizer (MGE) as a function of the torque variation was analyzed in a torque rheometer.

Figure 1 presents the results of the torque versus time for pure polymers $\left(\mathrm{PMMA}_{\text {elast }}\right.$ and PET) and PMMA $\mathrm{A}_{\text {elas }} / \mathrm{MGE}$ (95/5 wt\%) and PET/MGE (95/5 wt\%) mixtures. A significant increase in the torque value, both for PMMA elast and PET with the addition MGE was observed. The increase in the torque value of PET is related to the reaction that occurs between the epoxy group of MGE and the carboxyl and hydroxyl groups present at the end of the PET chain, whose results are found in literature on studies conducted in reactive compatibilization with poly (butylene terephthalate) (PBT), which has structure similar to $\mathrm{PET}^{[32,33]}$.

Figure 2 shows the analysis of $\mathrm{PMMA}_{\text {homo }} / \mathrm{MGE}$ and PMMA $_{\text {homo }} /$ MGE mixtures (95/5 wt\%), which analysis aim to investigate the increased torque in the PMMAelast/MGE mixture presented in Figure 1. The PMMA ${ }_{\text {homo }} / \mathrm{MGE}$ mixture showed no significant increase in torque compared to $\mathrm{PMMA}_{\text {homo }}$, thus there is indication that the reactivity between PMMA $A_{\text {elast }}$ and MGE is a function of the reactivity of the elastomeric particles of PMMA with the epoxy group of MGE.

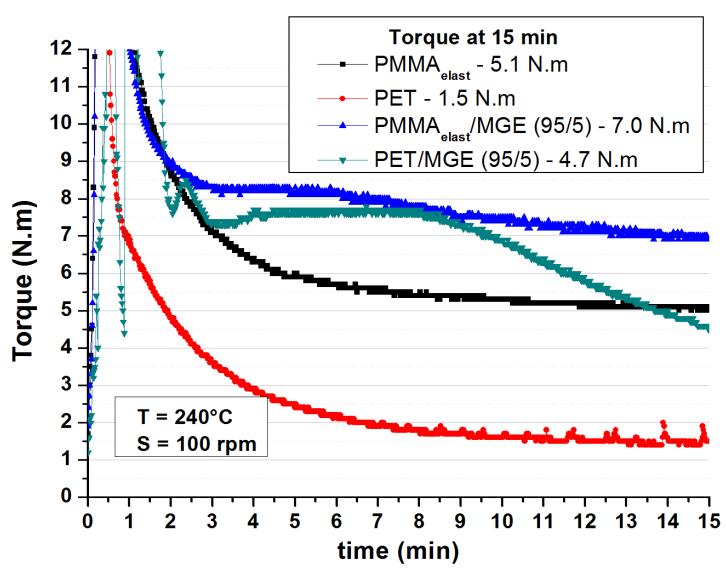

Figure 1. Torque versus time curves for PMMA ${ }_{\text {elast }}$ PET, PMMA $_{\text {elast }} / \mathrm{MGE}(95 / 5)$ and PET/MGE (95/5). 
An illustrative representation of reactions occurring

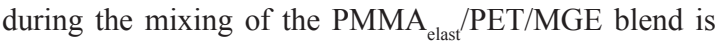
showed in Figure 3. The epoxy group of $\mathrm{MGE}^{[32,33]}$ reacts with end-chain groups (carboxyl and hydroxyl) of PET, and the increased torque of the PMMA elast $_{\text {MGE mixture }}$ is related to the possible reaction of the epoxy group of MGE with elastomeric particles of PMMA. The PMMA elast $_{\text {PMA }}$ is composed of homopolymer PMMA and copolymer PMMA with elastomeric particles (PMMA $\left.{ }_{\text {copo }}\right)$. Thus, there is a possibility of reactivity of MGE with PMMA and with PET, forming the complex interfacial structure PET- $g$-MGE- $g$-PMMA ${ }_{\text {elast }}$.

The torque $v s$. time curves for pure polymers and for binary blends in Figure 4 show that the PMMA elast $_{\text {had higher }}$ torque compared to PET, thus the increased percentage of PET in the binary blend leads to a proportional reduction of the torque value, i.e., reducing the viscosity of this mixture.

Figure 5 presents an increase in torque as a function of the addition of MGE to the binary blend with 30 to $15 \%$ by weight of dispersed phase PET. The results showed that the addition of MGE increases the torque of the PMMA ${ }_{\text {elast }} / \mathrm{PET}$ blend, where the first torque increase peak (not shown on graph) is due to the addition of the solid material before the softening and melting as a function of time and temperature. The second peak in the torque versus time curve that is displayed in the compatibilized blends is an indication of the dual reactivity of MGE with PMMA elast $_{\text {and PET. }}$

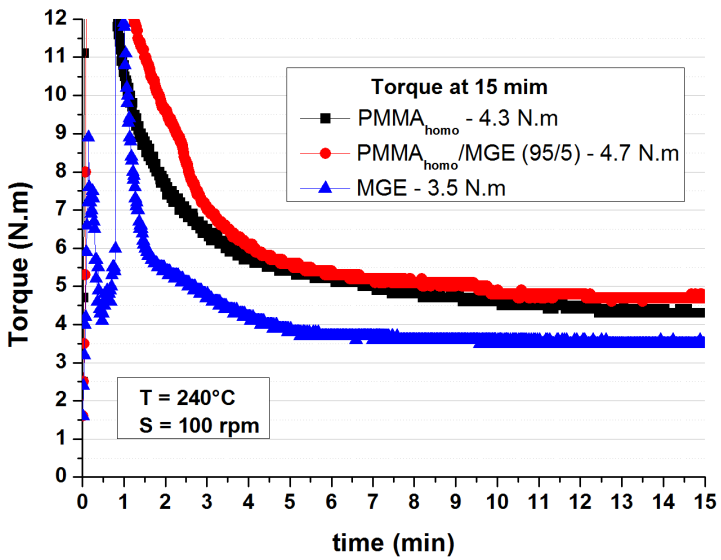

Figure 2. Torque versus time curves for PMMA $\mathrm{PMMA}_{\text {homo }} / \mathrm{MGE}(95 / 5)$ and MGE.

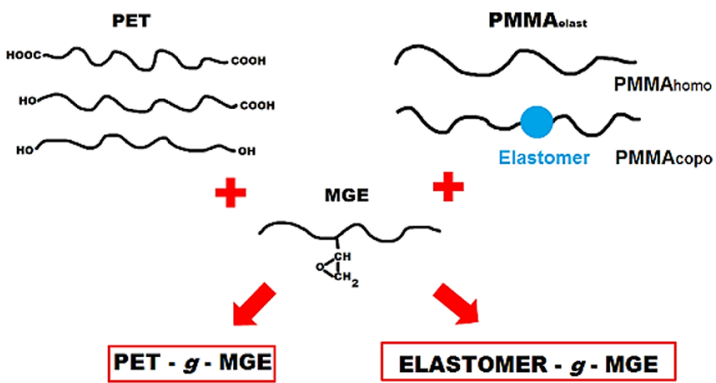

Figure 3. Illustrative representation of the reaction of MGE with end-chain groups of PET with the elastomeric phase of copolymer PMMA $\left(\right.$ PMMA $\left._{\text {elast }}=\mathrm{PMMA}_{\text {homo }}+\mathrm{PMMA}_{\text {copo }}\right)$.

\subsection{Mechanical characterization}

The mechanical properties of pure polymers $\left(\mathrm{PMMA}_{\text {elast }}\right.$ and PET) and of PMMA elast PET binary blends with and without the use of compatibilizing agent MGE are showed in Table 2 and Figure 6.

The PMMA ${ }_{\text {elast }}$ used in this study showed better elongation at break properties compared to commercial types of PMMA $^{[39]}$, due to the modification of the mechanical properties (toughening mechanisms ${ }^{[7-10]}$ ) caused by elastomeric particles.

The results of maximum strength and elastic modulus (Table 2 and Figure 6) showed that these properties increase as a function of the PET concentration in the binary blend and also due to the use of MGE.

The addition of PET as a dispersed phase reduced the elongation at break in the PMMA $\mathrm{P}_{\text {elast }} / \mathrm{PET}$ blend. However, in the blend with $30 \mathrm{wt} \%$ of PET compatibilized with $5 \mathrm{wt} \%$ of MGE, and in the binary blend with $50 \mathrm{wt} \%$ of PET, increase in this property (synergism) how has been observed in Figure 6c. These results indicate an efficient interfacial compatibilization by reducing the size of the dispersed phase, and co-continuous morphology, respectively.

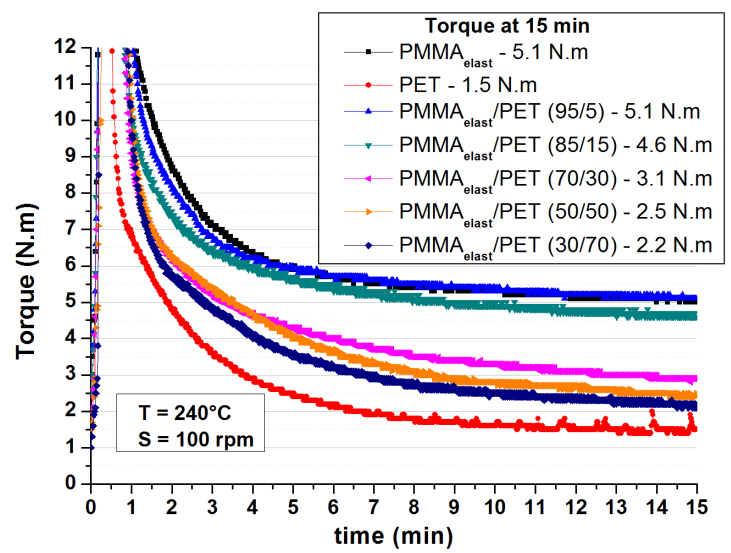

Figure 4. Torque versus time curves for pure polymers $\left(\mathrm{PMMA}_{\text {elast }}\right.$ and PET) and for binary blends (PMMA $\mathrm{Plas}_{\mathrm{PET}}$ ).

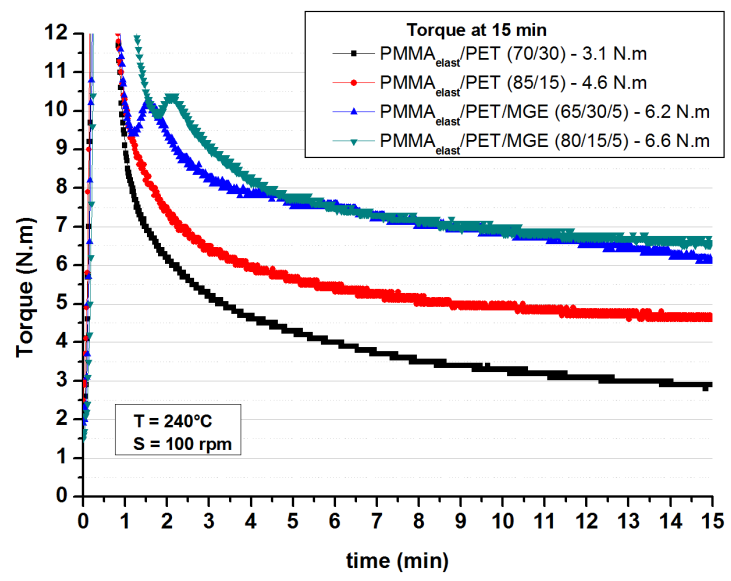

Figure 5. Torque versus time curves for $\mathrm{PMMA}_{\text {elast }} / \mathrm{PET}$ binary blends: $(70 / 30)$ and $(85 / 15)$ and PMMA $_{\text {elast }} / \mathrm{PET} / \mathrm{MGE}$ compatibilized blends: $(65 / 30 / 5)$ and $(80 / 5 / 15)$. 


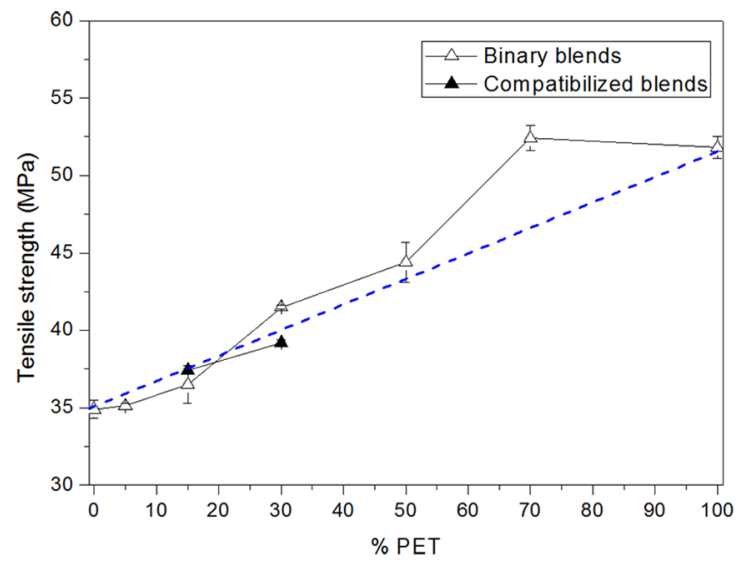

(a)

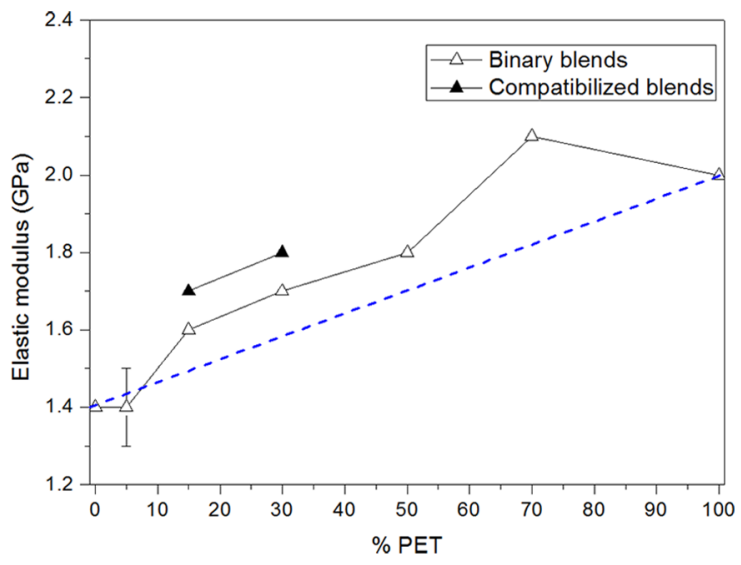

(b)

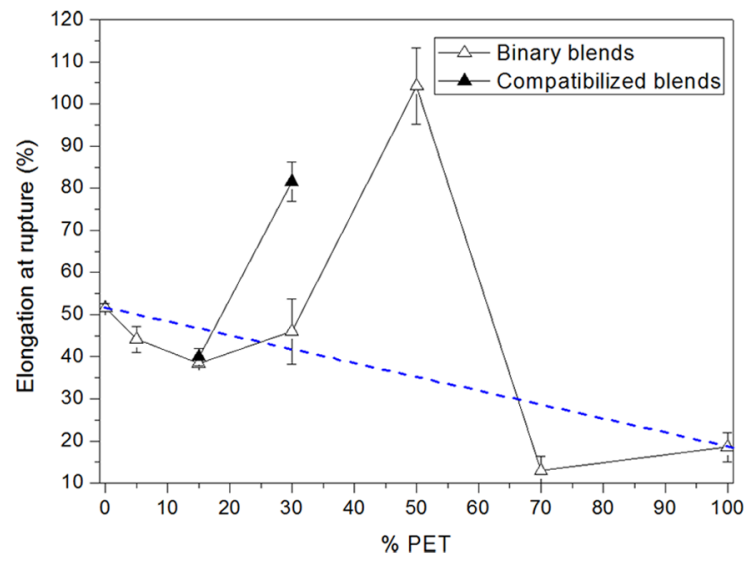

(c)

Figure 6. Mechanical properties of the PMMA elast $/$ PET binary blends in function of the PET concentration. (a) Tensile strength; (b) Elastic modulus; and (c) Elongation at rupture.

Table 2. Mechanical properties of pure polymers $\left(\right.$ PMMA $_{\text {elast }}$ and PET) and PMMA/PET and PMMA/PET/MGE blends.

\begin{tabular}{|c|c|c|c|}
\hline $\begin{array}{c}\text { Composition } \\
(w t \%)\end{array}$ & $\begin{array}{c}\text { Tensile strength } \\
\text { (MPa) }\end{array}$ & $\begin{array}{c}\text { Elastic modulus } \\
\text { (GPa) }\end{array}$ & $\begin{array}{c}\text { Elongation at rupture } \\
(\%)\end{array}$ \\
\hline PMMA $_{\text {elast }}(100)$ & $34.9 \pm 0.6$ & $1.4 \pm 0.1$ & $51.6 \pm 1.0$ \\
\hline PET $(100)$ & $51.8 \pm 0.7$ & $2 \pm 0.0$ & $18.5 \pm 3.4$ \\
\hline PMMA $_{\text {elas }} /$ PET $(95 / 5)$ & $35.1 \pm 0.2$ & $1.4 \pm 0.1$ & $44.1 \pm 3.1$ \\
\hline $\mathrm{PMMA}_{\text {elast }} / \mathrm{PET}(85 / 15)$ & $36.5 \pm 1.2$ & $1.6 \pm 0.1$ & $38.4 \pm 1.0$ \\
\hline $\mathrm{PMMA}_{\text {elast }} / \mathrm{PET}(70 / 30)$ & $41.5 \pm 0.1$ & $1.7 \pm 0.0$ & $46.0 \pm 7.8$ \\
\hline $\mathrm{PMMA}_{\text {elast }} / \mathrm{PET}(50 / 50)$ & $44.4 \pm 1.3$ & $1.9 \pm 0.0$ & $104.2 \pm 9.1$ \\
\hline PMMA $_{\text {elast }} /$ PET (30/70) & $52.4 \pm 0.8$ & $2.2 \pm 0.1$ & $12.9 \pm 3.5$ \\
\hline $\mathrm{PMMA}_{\text {elast }} / \mathrm{PET} / \mathrm{MGE}(80 / 15 / 5)$ & $37.4 \pm 0.1$ & $1.7 \pm 0.1$ & $39.9 \pm 2.1$ \\
\hline $\mathrm{PMMA}_{\text {elast }} / \mathrm{PET} / \mathrm{MGE}(65 / 30 / 5)$ & $39.2 \pm 0.2$ & $1.8 \pm 0.1$ & $81.6 \pm 4.7$ \\
\hline
\end{tabular}

Regarding to the blends with $15 \mathrm{wt} \%$ of PET in Figure $6 \mathrm{c}$, no significant increase in the elongation at break was observed. The compatibilization agents used and the weight percentage of PET are not enough to promoted the

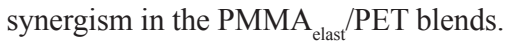

\subsection{Morphological characterization}

\subsubsection{Scanning electron microscopy}

Specific solvents can be used for phase extraction in polymer blends, allowing observing the morphology of the dispersed phase by electron microscopy techniques.
Chloroform is solvent of the PMMA and the phenol/1,1,2,2tetrachloroethane solution $(60 / 40 \mathrm{wt} \%)$ solubilizes the $\mathrm{PET}^{[40]}$; thus, these solvents can be used to extract phases present in the PMMA elast $_{\text {PET mixture. }}$

Figure 7 shows the morphology of PMMA ${ }_{\text {elast }}$ obtained after the extraction of phases using two solvents: chloroform and phenol/1,1,2,2-tetrachloroethane solution. Preliminary tests with chloroform showed that there is complete solubilization of PMMA ${ }_{\text {elast }}$ after 10 minutes under ultrasonic agitation. A structure of spherical voids are formed after 5 minutes

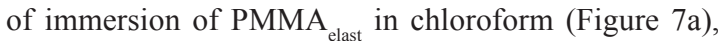




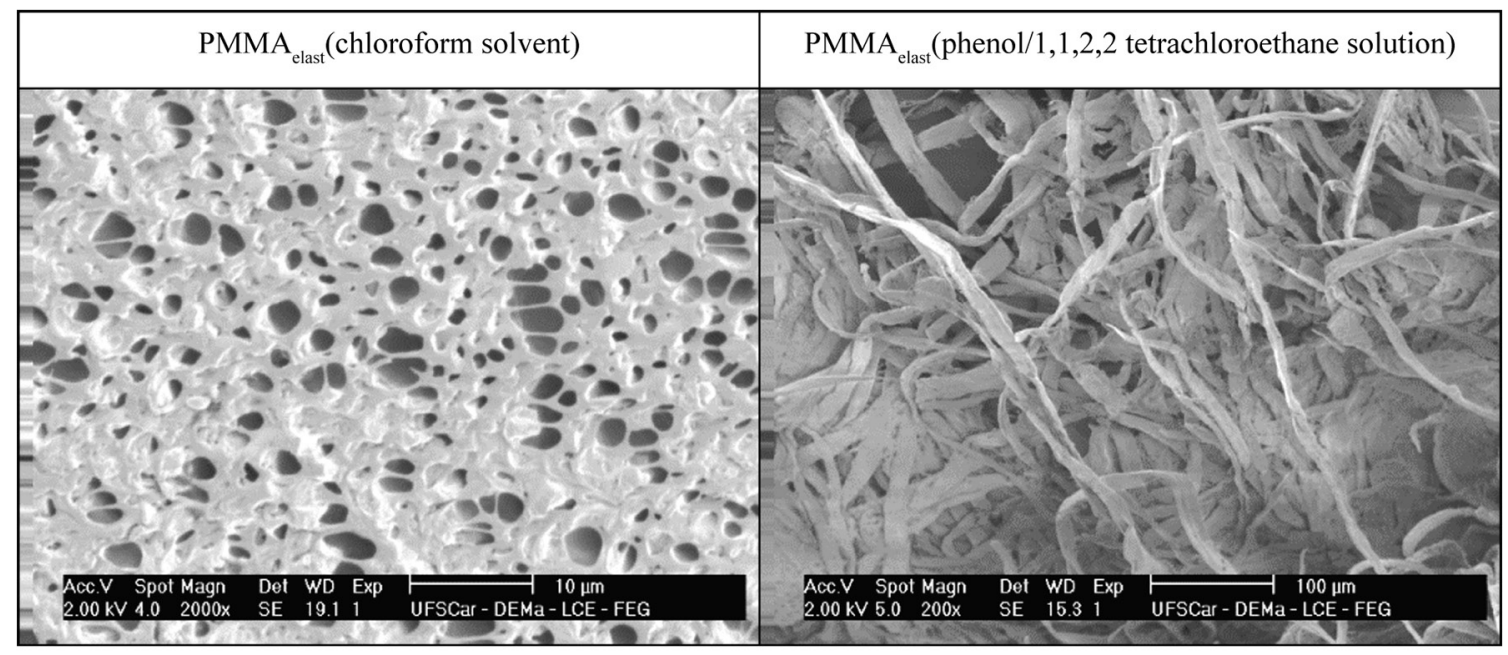

(a)

(b)

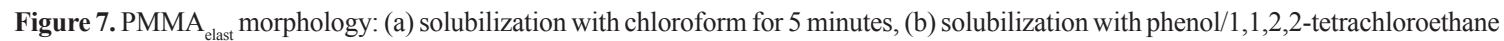
solution $(60 / 40 \% \mathrm{wt})$ for 15 minutes.

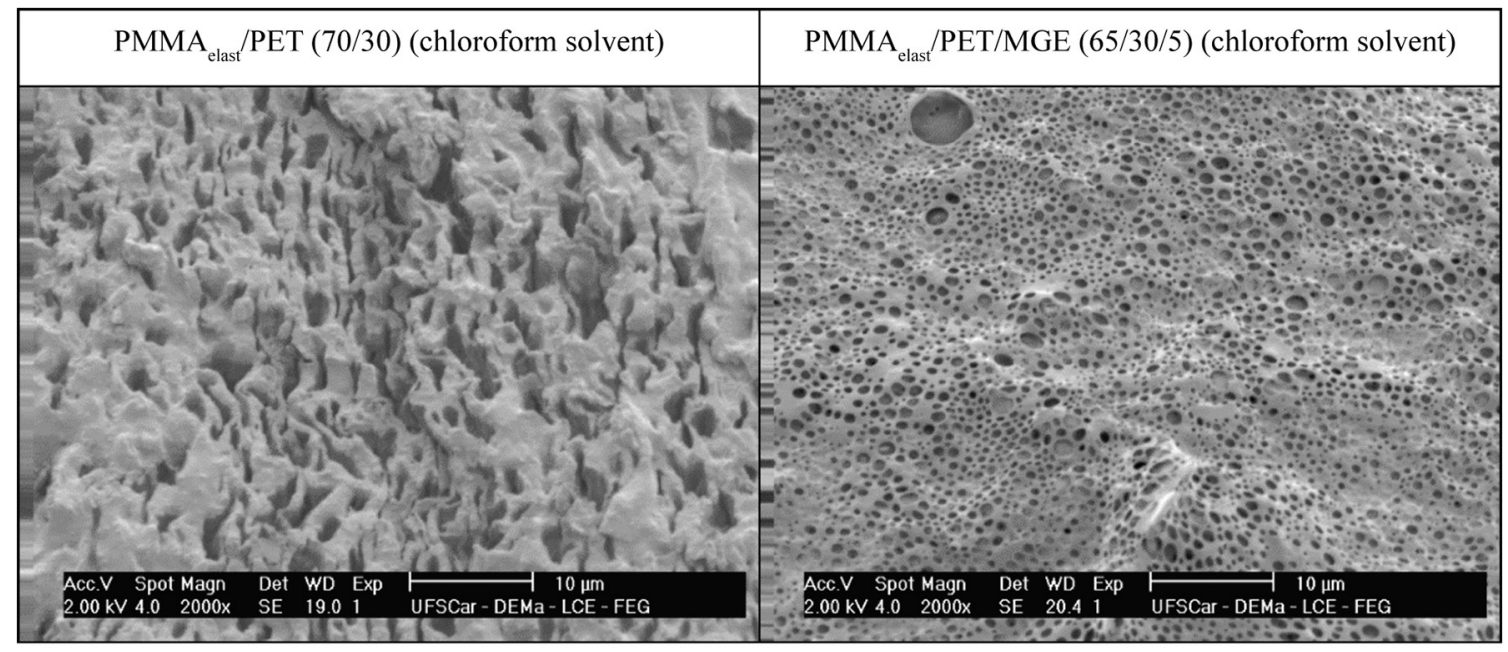

(a)

(b)

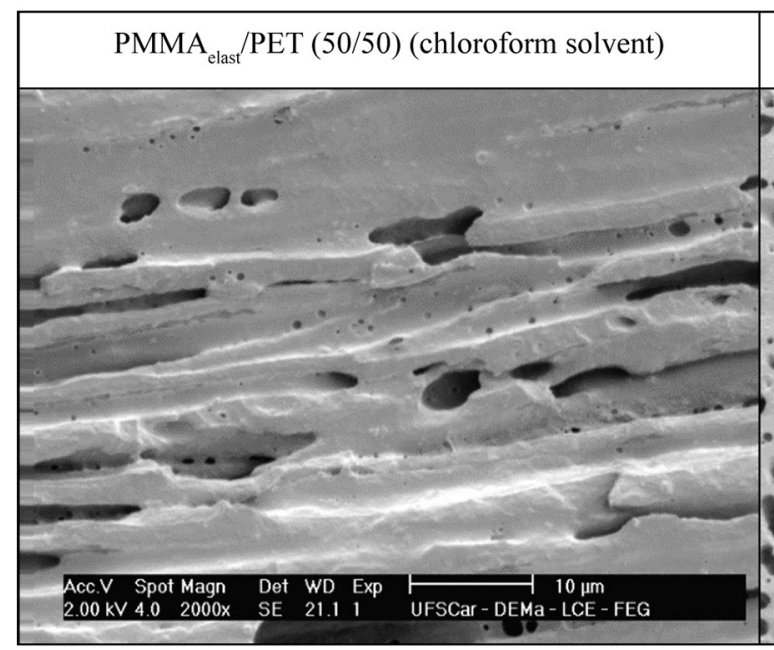

(c)

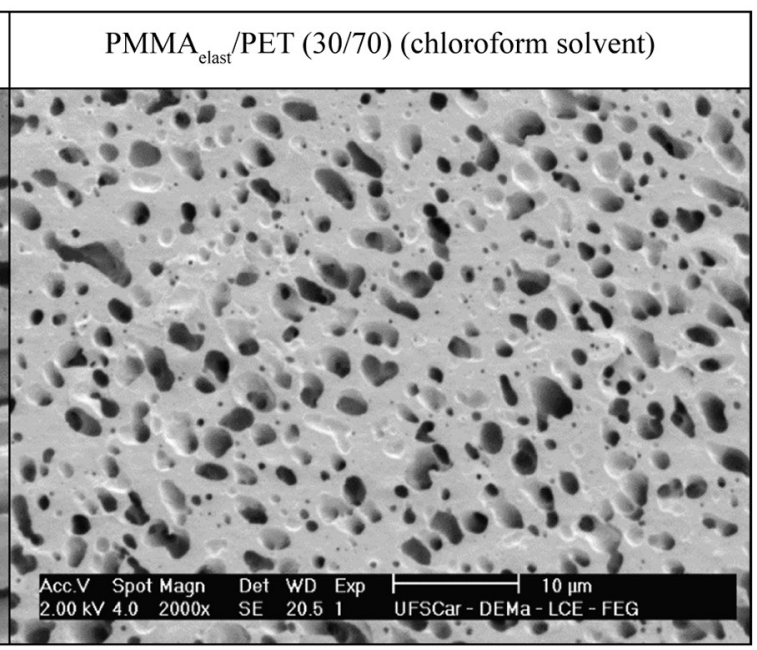

(d)

Figure 8. Morphology of PMMA elast $_{\text {PET and PMMA }}$ /PET/MGE blends: (a) (70/30), (b) (65/30/5) (c) (50/50) (d) (30/70) using chloroform for 15 minutes. 
which was an indication of preferential solubilization of elastomeric particles.

In Figure $7 \mathrm{~b}$, the phenol/1,1,2,2-tetrachloroethane solution was used as solvent with the aim of showing that the solution does not react with the PMMA structure. However, the morphology of fibrillar dispersed phase was verified, which appears after the immersion of PMMA in the phenol/1,1,2,2-tetrachloroethane solution. This result corroborates the illustrative representation of Figure 3, where $\mathrm{PMMA}_{\text {elast }}$ is composed of homopolymer PMMA $\left(\mathrm{PMMA}_{\text {homo }}\right)$ and copolymer PMMA with elastomeric particles $\left(\mathrm{PMMA}_{\text {copo }}\right.$ ). Therefore, the solvent is preferably solubilized with elastomeric particles, extracting PMMA and remaining the $\mathrm{PMMA}_{\text {homo }}$ phase, corresponding to the fibrillar phase shown in Figure $7 \mathrm{~b}$.

In Figure 8, chloroform is used as solvent for PMMA elast $_{\text {PET }}$ and PMMA $A_{\text {elast }} / \mathrm{PET} / \mathrm{MGE}$ blends. Preliminary test has confirmed that chloroform did not solubilize PET, so the voids shown in Figures 8a-d correspond to the PMMA phase, which was extracted with chloroform.
In Figure 8a, apparently, there was a collapse of the disperse phase PET due to the extraction of the major phase

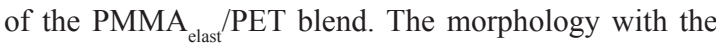
formation of spherical voids (Figure $8 \mathrm{~b}$ ) is an indication of extraction of elastomeric particles, keeping the structure of the PMMA ${ }_{\text {elast }} /$ PET blend as a function of the reactive compatibilization, corroborating synergism results observed in the elongation at break for this PMMA $\mathrm{elast}_{\mathrm{PET}} / \mathrm{MGE}$ blend $(65 / 30 / 5 \mathrm{wt} \%)$. The comparative analysis of the morphology of the binary blend (Figure 8a) with the same composition as the compatibilized blend (Figure 8b) showed a reduction in the size of the dispersed phase PET, increasing the surface area of PET particles and increasing the interaction with the PMMA matrix and thus increasing the matrix stability against the attack of solvents.

In PMMA $\mathrm{Plas}_{\text {las }} / \mathrm{PET}$ binary blends with $50 \mathrm{wt} \%$ of dispersed phase (Figure 8c), a co-continuous morphology was observed, which was confirmed by the synergism found in its mechanical properties when compared to the other blends before and after phase inversion.

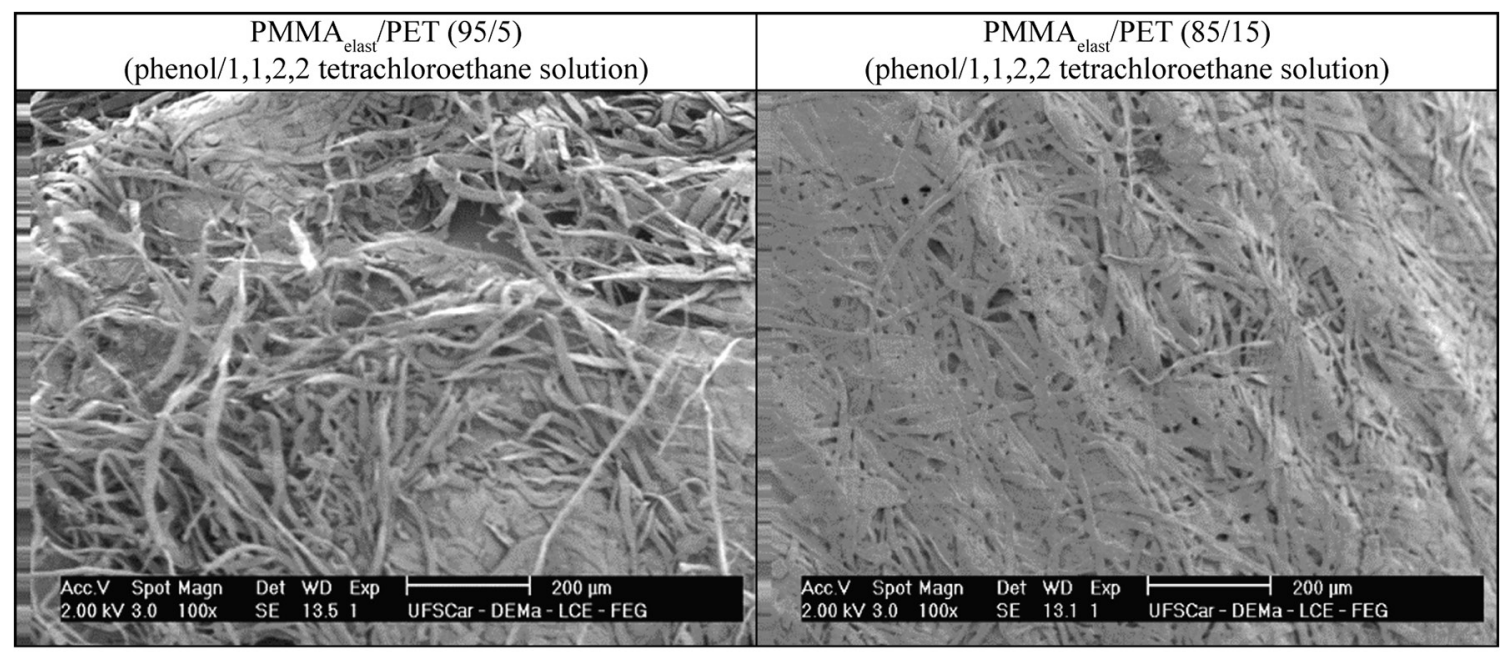

(a)

(b)

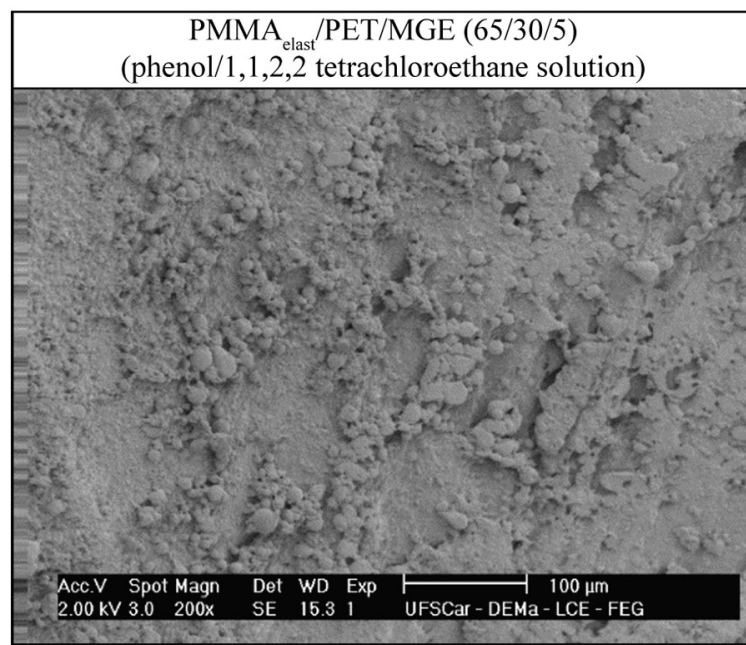

(c)
PMMA $_{\text {elast }} /$ PET/MGE (80/15/5) (phenol/1,1,2,2 tetrachloroethane solution)

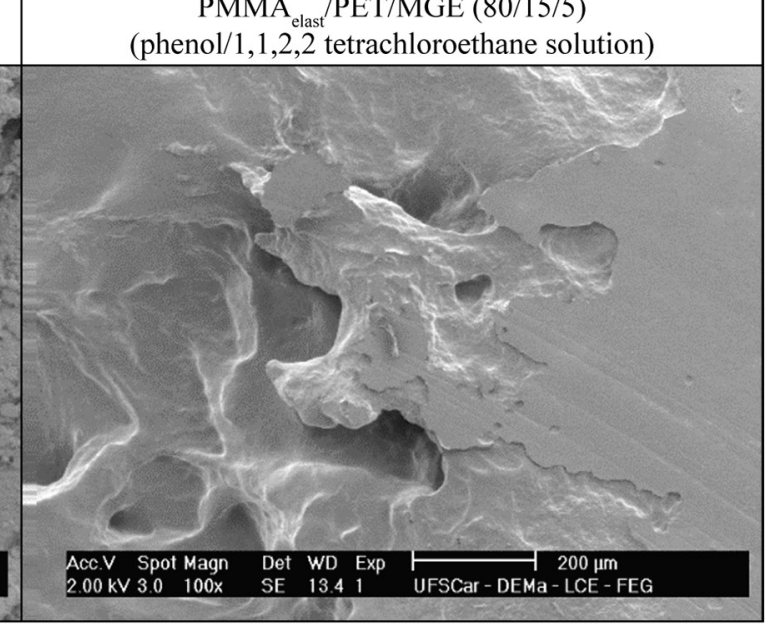

(d)

Figure 9. Morphology of $\mathrm{PMMA}_{\text {elast }} / \mathrm{PET}$ and PMMA ${ }_{\text {elast }} / \mathrm{PET} / \mathrm{MGE}$ blends (a) (95/5) (b) (85/15) (c) (65/30/5) and (d) (80/15/5) using phenol/1,1,2,2-tetrachloroethane solvent for 15 minutes. 


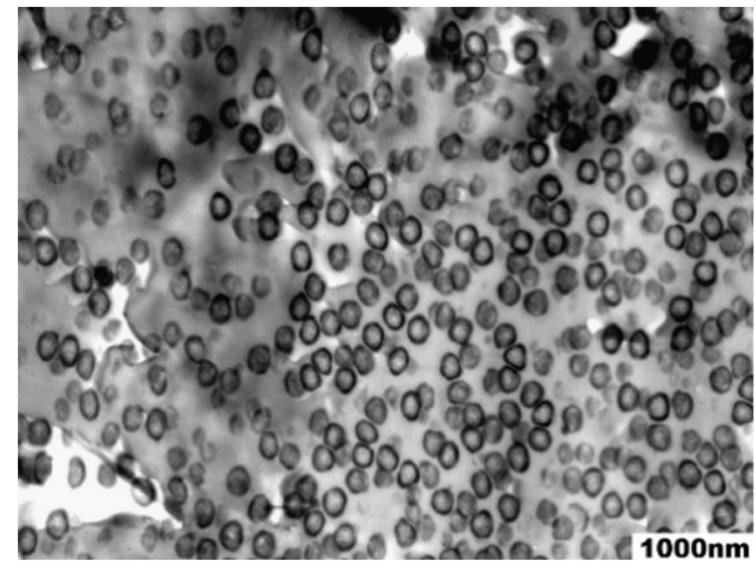

(a)

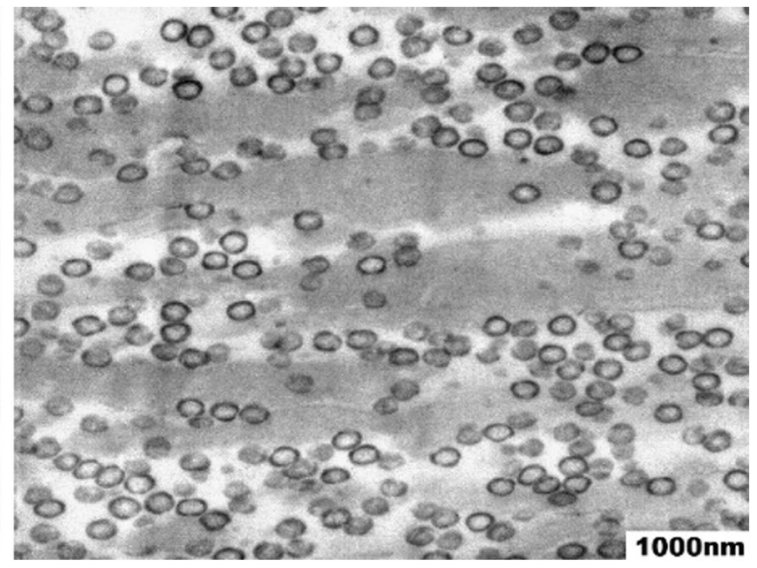

(b)

Figure 10. Morphology of PMMA elast $_{\text {PET and PMMA }}$ elast $/ \mathrm{PET} / \mathrm{MGE}$ blends: (a) (70/30) and (b) (65/30/5) stained with RuO $\mathrm{O}_{4}$ and obtained by TEM.

The photomicrograph of Figure 8d shows a surface with voids of irregular shapes, these voids were generated by extraction of the PMMA ${ }_{\text {elast }}$ dispersed phase in the PET matrix. This morphology also corroborated with the result of mechanical behavior, as the drastic reduction in the elongation at break, increase in the maximum strength, and elastic modulus, how a function of the PET matrix.

Figures $9 \mathrm{a}$ and $9 \mathrm{~b}$ show that the phenol/1,1,2,2tetrachloroethane solution favored the extraction of the elastomeric particles and the PET. The fibrillar morphology shown by this composition corresponds to $\mathrm{PMMA}_{\text {homo }}$.

For compatibilized blends (Figure 9c and 9d), the morphology was not sufficiently revealed. The MGE

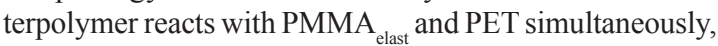
hindering the extraction of phase with the phenol/1,1,2,2 tetrachloroethane solution in PMMA $A_{\text {elast }}$ PET/MGE blends.

\subsubsection{Transmission electron microscopy}

In Figure 10, it was observed that the PMMA $A_{\text {elast }}$ PET blend showed a complex morphology, where the elastomeric

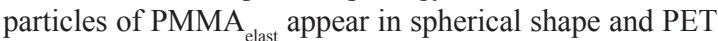
phase with the dark regions into the PMMA matrix.

The average diameter of elastomeric particles measured in Figure 10a and 10b are $300 \pm 20 \mathrm{~nm}$ and $290 \pm 20 \mathrm{~nm}$, respectively. These results confirm that elastomeric particles do not undergo changes in size with the addition of the compatibilizer. If the PMMA $A_{\text {elast }}$ was a polymer blend, the interaction between MGE and elastomeric particles would favor the reduction of the average diameters of these particles. These results corroborate with the morphologies shown by the extraction phase obtained by SEM (Figure 7, 8 and 9) for the PMMA $\mathrm{elast}_{\mathrm{PET}} / \mathrm{PElend}$ and by illustrative proposal shown in Figure 3.

\section{Conclusions}

The study of the rheological, morphological and mechanical behavior of immiscible and incompatible polymer blends constituted with poly (methyl methacrylate) with elastomeric particle and post-consumer poly (ethylene terephthalate)
$\left(\mathrm{PMMA}_{\text {elast }} / \mathrm{PET}\right)$ showed that these properties are directly correlated and vary depending on the composition and addition of the compatibilizer.

The addition of MGE terpolymer to the $\mathrm{PMMA}_{\text {elast }} / \mathrm{PET}$ blend increased the torque of both polymers, as shown in the rheological results. Thus, MGE reacts with PMMA ${ }_{\text {elast }}$ and PET, corroborating with the changes in the PMMA ${ }_{\text {elast }} / \mathrm{PET}$ blends properties.

The results of the elongation at break in the mechanical tests were conclusive to evidence the co-continuous morphology

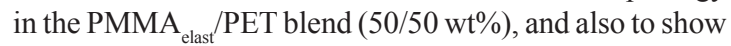
the effectiveness of the dual reactive compatibilization in the blend with $30 \mathrm{wt} \%$ of PET dispersed phase with $5 \mathrm{wt} \%$ of MGE.

The morphological study using solvents aided in the visualization of spherical particles in the elastomeric phase of PMMA ${ }_{\text {elast }}$ and showed that the PMMA $A_{\text {elast }}$ is composed of a PMMA ${ }_{\text {homo }}$ phase and another PMMA copo $_{\text {elast }}$ phase.

It was concluded that the PMMA elast $_{\text {PET blend }}$ compatibilized by MGE terpolymer has complex morphology that can be better understood in this work.

\section{Acknowledgements}

The authors would like to thank company Unigel for providing poly (methyl methacrylate) used in this work. To Brazilian funding agencies REUNI-CAPES, CNPq and FINEP for financial support and infrastructure.

\section{References}

1. Utracki, L.A. (1989). Polymer alloys and blends: thermodynamics and rheology. Munich: Hanser.

2. Utracki, L. A. (1995). History of commercial polymer alloys and blends. Polymer Engineering and Science, 35(1), 2-17. http://dx.doi.org/10.1002/pen.760350103.

3. Roenbson, L. M. (2007). Polymer blends: a comprehensive review. Munich: Hanser.

4. Brydson, J. A. (1999). Plastics materials (7th ed.). Oxford: Butterworth-Heinemann. 
5. Mark, J. E. (1999). Polymer data handbook. New York: Oxford University Press.

6. Mano, E. B. (2003). Polímeros como materiais de engenharia. São Paulo: Edgard Blucher.

7. Bucknall, C. B. (1977). Toughened plastics. London: Applied Science. http://dx.doi.org/10.1007/978-94-017-5349-4.

8. Ayre, D. S., \& Bucknall, C. B. (1998). Particle cavitation in rubber-toughened PMMA: experimental testing of the energybalance criterion. Polymer, 39(20), 4785-4791. http://dx.doi. org/10.1016/S0032-3861(97)10253-1.

9. Bucknall, C. B., Rizzieri, R., \& Moore, D. R. (2000). Detection of incipient rubber particle cavitation in toughened PMMA using dynamic mechanical tests. Polymer, 41(11), 4149-4156. http://dx.doi.org/10.1016/S0032-3861(99)00639-4.

10. Lalande, L., Plummer, J. G., Manson, J.-A. E., \& Gérard, P. (2006). Microdeformation mechanisms in rubber toughened PMMA and PMMA-based copolymers. Engineering Fracture Mechanics, 73(16), 2413-2426. http://dx.doi.org/10.1016/j. engfracmech.2006.05.014.

11. Carvalho, F. P., Gonçalves, M. C., \& Felisberti, M. I. (2012). Effect of in situ polymerization conditions of methyl methacrylate on the structural and morphological properties of poly(methyl methacrylate)/poly(acrylonitrile-g-(ethylene-co-propyleneco-diene)-g-styrene) PMMA/AES blends. Journal of Applied Polymer Science, 124(4), 2846-2856. http://dx.doi.org/10.1002/ app.35337.

12. Cocco, D. R., Carvalho, F. P., \& Felisberti, M. I. (2013). Structures and morphologies of in situ polymerized blends of PMMA and ASA. Journal of Applied Polymer Science, 130(1), 654-664. http://dx.doi.org/10.1002/app.39188.

13. Todo, M., Takahashi, J., Watanabe, H., Nakamoto, J., \& Arakawa, K. (2006). Effect of loading-rate on fracture micromechanism of methylmethacrylate-butadiene-styrene polymer blend. Polymer, 47(13), 4824-4830. http://dx.doi.org/10.1016/j. polymer.2006.04.042.

14. Cheng, T. W., Keskkula, H., \& Paul, D. R. (1992). Property and morphology relations for ternary blends of polycarbonate, brittle polymers and impact modifier. Polymer, 33(8), 16061619. http://dx.doi.org/10.1016/0032-3861(92)91056-8.

15. Zhou, C., Chen, M., Tan, Z. Y., Sun, S. L., Ao, Y. H., Zhang, M. Y., Yang, H. D., \& Zhang, H. X. (2006). The influence of arrangement of St in MBS on the properties of PVC/MBS blends. European Polymer Journal, 42(8), 1811-1818. http:// dx.doi.org/10.1016/j.eurpolymj.2006.03.017.

16. Chen, X. D., Wang, J. S., \& Shen, J. R. (2006). Effect of the shell thickness of methacrylate-butadiene-styrene core-shell impact modifier on toughening polyvinyl chloride. Journal of Polymer Research, 13(4), 335-341. http://dx.doi.org/10.1007/ s10965-006-9048-8.

17. Aerdts, A. M., Groeninckx, G., Zirkzee, H. F., van Aert, H. A. M., \& Geurts, J. M. (1997). Preparation of epoxy-functionalized methyl methacrylate-butadiene-styrene core-shell particles and investigation of their dispersion in polyamide-6. Polymer, 38(16), 4247-4252. http://dx.doi.org/10.1016/S0032-3861(96)01003-8.

18. Mano, E. B., \& Mendes, L. C. (1999). Introdução a polímeros (2nd ed.). São Paulo: Edgard Blucher.

19. Romão, W., Spinacé, M. A. S., \& De Paoli, M. A. (2009). Poli(tereftalato de etileno), PET: uma revisão de processos de síntese, mecanismos de degradação e sua reciclagem. Polímeros: Ciência e Tecnologia, 19(2), 121-132. http://dx.doi. org/10.1590/S0104-14282009000200009.

20. Bannach, G., Perpértuo, G. L., Cavalheiro, E. T. G., Cavalheiro, C. C. S., \& Rocha, R. R. (2011). Efeitos da história térmica nas propriedades térmicas do polímero PET: um experimento para ensino de análise térmica. Quimica Nova, 34(10), 1825-1829. http://dx.doi.org/10.1590/S0100-40422011001000016.

21. Paul, D. R., Barlow, J. W., \& Keskkula, H. (1988). Encyclopedia of polymer blend systems. New York: John Wiley \& Sons.

22. Canevarolo, S. V., Jr. (2006). Ciencia dos polímeros: um texto básico para tecnólogos e engenheiro (2nd ed.). São Paulo: Artliber.

23. Coelho, T. M., Castro, R., \& Gobbo, J. A., Jr (2011). Containers in Brazil: opportunities and challenges of a logistics model for post-consumer waste recycling. Resources, Conservation and Recycling, 55(3), 291-299. http://dx.doi.org/10.1016/j. resconrec.2010.10.010.

24. Welle, F. (2011). Twenty years of PET bottle to bottle recycling: an overview. Resources, Conservation and Recycling, 55(11), 865-875. http://dx.doi.org/10.1016/j.resconrec.2011.04.009.

25. Welle, F. (2013). Is PET bottle-to-bottle recycling safe? Evaluation of post-consumer recycling processes according to the EFSA guidelines. Resources, Conservation and Recycling, 73, 41-45. http://dx.doi.org/10.1016/j.resconrec.2013.01.012.

26. Scheirs, J. (1998). Polymer recycling: science, technology and applications. New York: John Wiley \& Sons.

27. Kerboua, N., Cinausero, N., Sadoun, T., \& Lopez-Cuesta, J. M. (2010). Effect of organoclay in an immiscible poly(ethylene terephtalate) waste/poly(methyl methacrylate) blend. Journal of Applied Polymer Science, 117(1), 129-137. http://dx.doi. org/10.1002/app.31968.

28. Mallette, J. G., Márquez, A., Manero, O., \& Castro-Rodríguez, R. (2000). Carbon black filled PET/PMMA blends: electrical and morphological studies. Polymer Engineering and Science, 40(10), 2272-2278. http://dx.doi.org/10.1002/pen.11359.

29. Utracki, L. A. (2002). Compatibilization of polymer blends. Canadian Journal of Chemical Engineering, 80(6), 1008-1016. http://dx.doi.org/10.1002/cjce.5450800601.

30. Koning, C., Van Duin, M., Pagnoulle, C., \& Jerome, R. (1998). Strategies for compatibilization of polymer blends. Progress in Polymer Science, 23(4), 707-757. http://dx.doi.org/10.1016/ S0079-6700(97)00054-3.

31. Fink, J. K. (2005). Reactive polymers fundamentals and applications: a concise guide to industrial polymers (2nd ed.). New York: William Andrew Publishing.

32. Hale, W., Keskkula, H., \& Paul, D. R. (1999). Compatibilization of PBT/ABS blends by methyl methacrylate-glycidyl methacrylateethyl acrylate terpolymers. Polymer, 40(2), 365-377. http:// dx.doi.org/10.1016/S0032-3861(98)00189-X.

33. Larocca, N. M., Ito, E. N., Rios, C. T., Pessan, L. A., Bretas, R. E. S., \& Hage, E., Jr. (2010). Effect of PBT molecular weight and reactive compatibilization on the dispersed-phase coalescence of PBT/SAN blends. Journal of Polymer Science. Part B: Polymer Physics, 48(21), 2274-2287. http://dx.doi. org/10.1002/polb.22110.

34. Bretas, R. E. S., \& D’ Ávila, M. A. (2005). Reologia de polímeros fundidos. São Carlos: EdUFSCar.

35. Araújo, E. M., Hage, E., Jr, \& Carvalho, A. J. F. (2003). Compatibilização de blendas de poliamida 6/ABS usando os copolímeros acrílicos reativos MMA-GMA e MMA-MA. Parte 1: comportamento reológico e propriedades mecânicas e propriedades mecânicas das blendas. Polimeros: Ciências e Tecnologia, 13(3), 205-211. http://dx.doi.org/10.1590/S010414282003000300011.

36. Xanthos, M. (1992). Reactive extrusion: principles and practice. New York: Oxford University Press.

37. Ito, E. N., Silva, W. T. L., Marconcini, J. M., Ribeiro, C., Magalhães, W. L. E., Hage, E., Jr., \& Mattoso, L. H. C. 
(2007). Effect of processing on the properties of poly(methyl methacrylate)/sílica nanocomposites. In 23rd Polymer Processing Society Annual Meeting. Salvador.

38. Dewangan, B., \& Jagtap, R. N. (2006). Amphiphilic block copolymers of PtBA-b-PMMA as compatibilizers for blends of PET and PMMA. Polymer Engineering and Science, 46(9), 1147-1152. http://dx.doi.org/10.1002/pen.20577.

39. Dantas, R. L. F. (2011). Estudo morfológico da blenda polimérica poli(metacrilato de metila)/poli(tereftalato de etileno) reciclado
PMMA/PET (Dissertação de mestrado). Universidade Federal do Rio Grande do Norte, Natal.

40. Brandrup, J., Immergut, E. H., \& Grulke, E. A. (1982). Polymer handbook (4th ed.). New York: John Wiley \& Sons.

Received: Sept. 12, 2014

Revised: Feb. 27, 2015

Accepted: Mar. 30, 2015 